\title{
Realising potentials for arts-based sustainability science
}

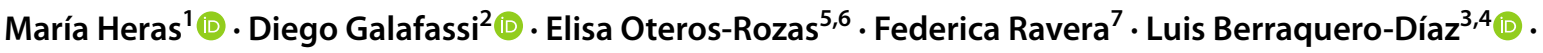 \\ Isabel Ruiz-Mallén ${ }^{1} \mathbb{D}$
}

Received: 16 October 2020 / Accepted: 4 July 2021 / Published online: 6 August 2021

(c) The Author(s) 2021

\begin{abstract}
In recent years, a profusion of methods, practices, and experiences has emerged in the interface between arts and sustainability science. Drawing from two strong currents within sustainability science, namely, the emphasis on transdisciplinary approaches and the need to move towards societal transformations, such hybrid approaches seemingly contribute with unique methods to sustainability research. Despite repeated claims from sustainability scientists about art's role in sustainability transformations, joint analyses with artists and practitioners are still rare. We conveyed a collaborative and exploratory workshop with scientists, artists, and practitioners from the fields of education, public engagement, and activism to identify the potentials for arts-based sustainability research. Participants were invited to facilitate and trial various artistic practices from disciplines of performative, literary, narrative, audio-visual and plastic arts. In this paper, we present five key areas identified in the workshop, where arts-based methods can significantly contribute to sustainability research: embracing morethan-cognitive aspects of knowledge, improving communication, grappling with power dynamics, shifting relationships to nature, and facilitating futures visioning. Workshop participants also identified challenges related to power dynamics, tensions across paradigms, and implementation conditions, providing insights into how to leverage arts' potential to respond to global environmental challenges while boosting societal transformations. We then discuss research questions identified that address challenges and limitations for arts-based research in sustainability. Overall, these results suggest there are yet untapped resources and experiences within the field of arts-based sustainability science. (Audio-visual abstract available on S1)
\end{abstract}

Keywords Knowledge systems $\cdot$ Art/science $\cdot$ Transformations $\cdot$ Methodology $\cdot$ Emotions $\cdot$ Co-creation

Handled by Rene Kemp, UNU-Maastricht Economic and Social Research and Training Centre on Innovation and Technology (MERIT), Netherlands.

$\triangle$ Diego Galafassi

diego.galafassi@lucsus.lu.se

María Heras

mheras0@uoc.edu

1 Internet Interdisciplinary Institute (IN3), Universitat Oberta de Catalunya (UOC), Av Carl Friedrich Gauss, 08860 Castelldefels, Barcelona, Spain

2 LUCSUS, Lund University, Box 170, 22100 Lund, Sweden

3 Pablo de Olavide University, Seville, Spain

4 Urban Resilience Research Lab, Seville, Spain

5 Chair On Agroecology and Food Systems, University of Vic - University of Central Catalonia, Barcelona, Spain

6 FRACTAL Collective, Barcelona, Spain

7 Departament de Geografia, Universitat de Girona Edifici Sant Domènec II Pl. Ferrater I Mora, 1 Campus Barri Vell, 17004 Girona, Spain

\section{Introduction}

In recent years, several works within sustainability science have pointed out the role of the arts in contributing to the understanding of the challenges of global environmental change (Ecology \& Society special issue on Reconciling Art and Science for Sustainability, ${ }^{1}$ Saratsi et al. 2019; Pereira et al. 2019; Heras 2015). As forms of research, but different from conventional science, the arts provide alternative explorative means for approaching reality and expanding our understanding of qualitative experience (Eisner 2002). Researchers claim the arts can advance sustainability science by embracing transdisciplinarity and expanding conventional epistemologies towards practical, embodied, and emotional domains (Pröpper 2017; Heinrichs \& Kagan 2019; Scheffer et al. 2015). Artists have also increasingly drawn from sustainability science insights to develop novel artistic practices dealing with mounting social-ecological challenges (Gabrys 1 https://www.ecologyand society.org/issues/view.php? sf=112 Accessed October 2020 
and Yusoff 2012; Galafassi et al. 2018a). This mutual interest suggests a potential space for the development of hybrid practices (Benessia et al. 2012).

"Arts-based research" is an umbrella term coined by Eisner in the early 1990s, referring to a transdisciplinary approach to knowledge building, based on the integration of artistic practices within social and scientific research contexts (Leavy 2018; McNiff 2011). Although the term encompasses different practices and terminologies (see, for instance, Chilton and Leavy 2014), across them, research is developed through artistic practices, treating art as a method at different stages of the research process, from data collection to representation and communication (Scrivener 2009 in Johnson 2010; Leavy 2009). Epistemologically, arts-based research assumes the acts of creating and experiencing art can generate meaning (Barone and Eisner 2012). The notion of research through art emphasises the process of knowing as inquiry, in contrast with knowledge, as a body of propositional statements (Johnson 2010). As such, art experiences constitute forms of knowing that include more-than-rational aspects such as creativity, imagination, emotions, motivations and values (Kagan 2011) and recognise the role of the body and sensory-motor processes in our capacity for understanding and knowing (Johnson 2010, p.145).

The profusion of arts-based methods and experiences within sustainability science sits within two strong currents in the field: the need to move towards societal transformations and the growing role of transdisciplinary approaches. Sustainability science has widely recognised that fundamental transformations are required to move towards a sustainable and just world (Sachs et al. 2019). Transformations have been conceptualised and studied in diverse ways, but overall, they refer to fundamental changes in structure, function, and relations at the personal, political and practical spheres of interdependent social, ecological, and technical systems, leading to new patterns of interactions and outcomes (O'Brien 2018; Feola 2015). This definition includes cultural transformations, which affect groups and societies' cultural roots, including beliefs, behaviours, values and worldviews (Westley et al. 2011; Horlings 2015).

Several authors have pointed out that sustainability research also needs to transform (Fazey et al. 2018). Two distinct streams have been observed in sustainability science; namely the 'descriptive-analytical', focused on analysing complex sustainability problems, and the 'transformational', which aims at (co)providing evidence-based solutions for them (Wiek and Lang 2016). Conducting transformational sustainability research involves adopting open and transdisciplinary methodological approaches capable of engaging with those enacting potential transformational solutions (Miller et al. 2013; Clark et al. 2016). Transdisciplinary approaches refer to research where scientists work together with policy-makers, communities, and interest groups to co-create questions and research processes that are transparent, legitimate, and salient (Clark et al. 2016). An increasing number of experiences with the arts in transdisciplinary spaces has been observed in recent years (Galafassi et al. 2018a, b; Saratsi et al. 2019). Feminist writers also argue for the need to move towards approaches that can articulate the dynamic relationships "between living things and multiple milieus" (Hughes and Lury 2013) and the situatedness of perspectives (Haraway 1999). Similarly, some of the most influential currents with contemporary sustainability science extend from paradigmatic shifts in the twentieth century on living systems theory (Bailey 1994), complexity theory (Kauffman 1996), and adjacent strands that acknowledge the entwinedness of humans and nature. This included a move from modes of prediction and control to open-ended processes that reconcile modern divides between values and facts, reason and more-than-rational, knowledge and experience (Ferraro and Reid 2013; Benessia et al. 2012). Such calls for novel ontological and epistemological departures have often led to proposals of working with arts. This is the case, for instance, of Benessia et al.'s (2012) suggestion of hybrid sustainability science and artistic practices, or Ruiz-Trejo and García-Dauder's (2019) proposition of epistemic-corporeal workshops focused on body and emotions as spaces for researchers to discuss their work and explore embodied and experiential knowledge.

Many roles have been suggested for the arts in the context of sustainability transformations and transdisciplinary including integrating fragmentary views of the world in holistic ways (Heras and Tàbara 2014), propelling creative imagination and serendipity (Kagan 2011, Galafassi 2018b), engaging with storytelling and visions of future (Dahlstrom 2014; Milkoreit 2017; Pereira et al. 2019), coupling socialecological change and culture while engaging with socialecological complexity (Tàbara and Chabay 2013), disclosing forms of oppression, challenging power dynamics and fostering dialogue where other methods failed (Boal 2006; Fernández-Giménez et al. 2019).

Although this interface has been partially addressed either from an artistic or a scientific perspective, there has not yet been a joint analysis with artists and scientists to understand how in practice, the arts contribute to new modes of research within sustainability science addressing societal transformations. To address this, the present article shares the experience of a 2-day exploratory workshop bringing together artists, researchers, and practitioners working in sustainability-related issues to explore the frontiers of social-ecological research for transformations and art-based approaches. Participants shared their expertise through experiential sessions, exhibitions, talks, and moments of collective reflection and inspiration. They co-created questions and insights to understand challenges and potentials at this interface and possible 
leverage points to make the art-science interface more effective towards sustainability goals.

From the joint analysis of workshop reflections and discussions, we identify and discuss five overarching areas of potential contribution to sustainability research of the diverse arts-based practices explored, as well as a set of critical questions related to tensions and challenges of these practices. In doing this, our study responds to the need to showcase and analyse how different arts-based methodological approaches are being used within sustainability science in various settings and their motivations, to better understand their transformational potential. In the next section, we describe the workshop methodology before we turn to present and discuss the results of our collaborative exploration.

\section{Methods}

\section{Workshop goals and approach}

Overall, the goal of the workshop was to explore the potential of arts-based research in sustainability science by bringing together artists from different artistic disciplines, researchers, and practitioners working on sustainability issues, as well as hybrid profiles between these categories, to experientially interrogate such potential and expand discussions in the field. While designing the workshop, our intention was to create a space where participants could experiment, reflect, and explore together, hence these direct experiences were a central component of the gathering.

The core organising team (i.e. the authors of this paper), was composed of scientists from different disciplines (e.g. anthropology, biology, environmental science) with artistic training or experience in the fields of film and audiovisual arts, music, physical theatre, dance, and narrative arts. Despite our hybrid backgrounds, our interest in such dialogue springs from our scientific work within sustainability science. Hence, our workshop and subsequent analysis approach have a stronger emphasis on sustainability science concepts and approaches.

The process of designing the workshop was itself an experience through which we engaged in a creative and open dialogue. Such dialogue also involved other people beyond academia, including artists. It was self-facilitated with techniques based on mindfulness, movement and embodiment to identify motivations to engage in the arts-science interface and meaningful questions to address in the workshop. Accordingly, the design process was already an attempt to position ourselves and put into play the kinds of open and collaborative spaces we wanted to generate. The organisation was highly collaborative within the team and with local networks in Barcelona, not least for budgetary constraints, but also as a collaborative resourcing and design.

\section{Implementation}

The two-day workshop was held in November 2016 in Barcelona. We published an open call for applications around four sustainability themes: (i) ecological functions and processes: inviting natural scientists and artists who may portray the current state and alert on trends of ecological systems through interacting with artistic practices; (ii) social-ecological interactions: calling for social and natural science research approaches which may interconnect biophysical, institutional, political, socio-economic and cultural dimensions of sustainability through the arts; (iii) ecological and justice conflicts: research approaches which reflect through arts on questions of justice and equity in the access and management of natural resources; (iv) participation, social learning and citizen engagement: arts-based research projects or socially engaged art projects engaging and encouraging participation of communities and diverse groups around sustainability issues.

Forty-three participants from nine countries (Spain, Portugal, UK, Germany, USA, Sweden, Netherlands, Belgium, Japan/Norway and Chile) attended the workshop. Excluding the organisers and taking into account participants' affiliations and roles in the workshop, 17 can be identified mainly as researchers, approaching sustainability from diverse disciplines (e.g. environmental sciences, social sciences, humanities, or several of them); 14 as artists, representing the fields of performing arts (dance, music, theatre, creative movement), audio- visual arts (video, film, paintings), plastic arts (sculpture, installations, artistic notebook) and narrative arts (poetry, storytelling); and five as practitioners, working on sustainability-related issues outside research (see Table 1). However, this categorisation is only indicative, as most of the participants were already operating within a hybrid space between arts and sciences, and many of them had a hybrid profile, either combining fields of action (research, activism, education) or being artists with a scientific background or scientists with artistic expertise (see S2 for more details on participants and the process).

We designed the workshop as a participatory encounter with different "moments" of action and individual and collective reflection related to the classical Kolb's experiential learning cycle (Kolb 1984). Accordingly, the workshop alternated different formats to facilitate spaces for active experimentation ('doing' and 'feeling' in Kolb's cycle), and spaces for reflective observation and abstract conceptualisation ('watching' and 'thinking'). Specifically, (i) eight parallel and interactive laboratories exploring different arts (theatre, dance, performance, storytelling, poetry, visual arts) were proposed as spaces for actively experiencing the 
Table 1 Methodological approaches shared in the workshop

\begin{tabular}{ll}
\hline Artistic genre & Hybrid methodological approaches applied by participants \\
\hline Body-based research and performance & Applied theatre \\
& Interplay: body, movement and voice \\
& Improvisation based on physical movement and voice expression \\
& Spoken word, poetry and acoustic singing \\
& Choreographic cartographies: dancing the landscape \\
Storytelling & Object-mediated storytelling about the future \\
Poetry & Poetry writing and dialogue \\
& Poetic analysis: documentary poetry \\
Film & Participatory video-documentary \\
& Feature film and transmedia elements \\
Sound installation & Sound performance and installation \\
Co-created mural & Collective creation: giant seed mandala \\
Sculpture & Art structures inspired by nature \\
& Functional artwork ("Do it Yourself" and digital fabrication) \\
Painting & Visual installation and sculptures (concrete, wood, iron and latex balloons) \\
Artistic Notebook & Future scenario paintings \\
Creative thinking techniques & Notebook compiling herbarium sheet, collage and the artist's notes \\
\hline
\end{tabular}

integration of arts in sustainability science; (ii) the presentation of 12 artistic works, related to audio-visual, performing and plastic arts, as sources of thinking and inspiration; (iii) five short talks as presentations of previous works and seeds for thought; (iv) a keynote conference, open to the wider public, for triggering reflections and abstract conceptualisations along the process; and (v) a social event in the evening including dance and poetry performance and open mics. Furthermore, both days ended with a final reflection session, as a collective space for sharing impressions and thoughts, which in the first day took the shape of a large mandala collaborative creation (for the full programme, see S2). Workshop labs, talks, and artistic works were selected according to four criteria: relevance (relevance to the workshop approach-methodological developments in arts-based sustainability science), robustness (internal coherence of the proposal), originality (how innovative), and technical aspects (adequacy and feasibility according to time, venues, resources). Further, to ensure diversity within participants and topics, we also took into account for each proposal: the topic(s) addressed, artistic approaches applied, participants' profile and country of origin (Fig. 1).

\section{Data collection and analysis}

The workshop process was documented using process observation, conducted by seven previously trained people (four of the organisers and three external researchers, with backgrounds in anthropology and environmental sciences) and using a common structured observation guide. Observation was supported with: (i) audio-visual recordings of moments of discussion and artistic interactions in most of

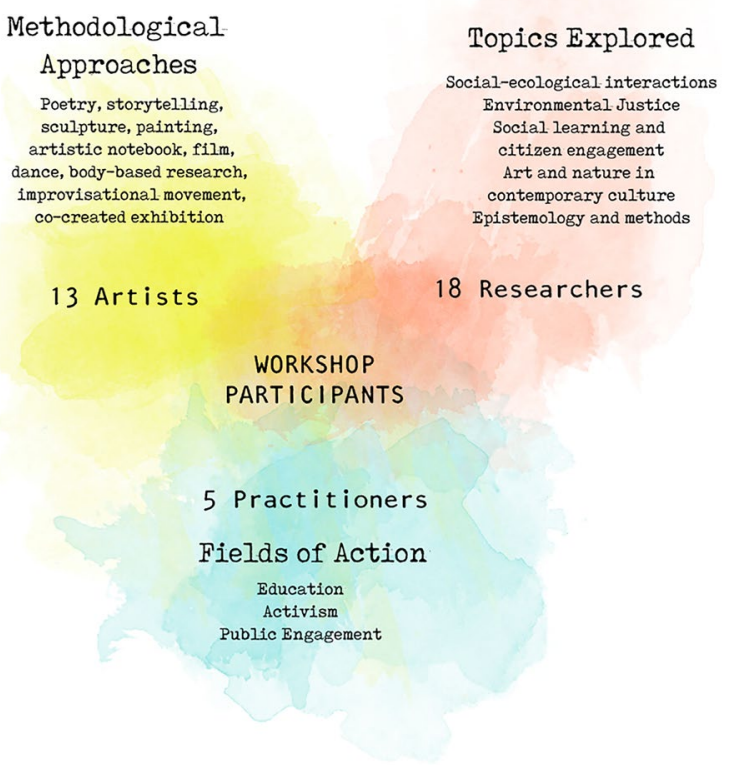

Fig. 1 Number of invited participants, arts-based methodological approaches shared, and topics explored

the sessions and informal interviews with several participants and facilitators; and (ii) a paper mural hanged on the coffee-break space, where participants were invited to write down or draw their reactions and reflections both during and after the workshop sessions (Fig. 2). Moreover, an online survey was conducted 2 weeks after the workshop to map participants' insights and reflections. The survey included eight questions approaching participants' experiences of the 
Fig. 2 Collective mural gathering participants reactions and reflections during the workshops

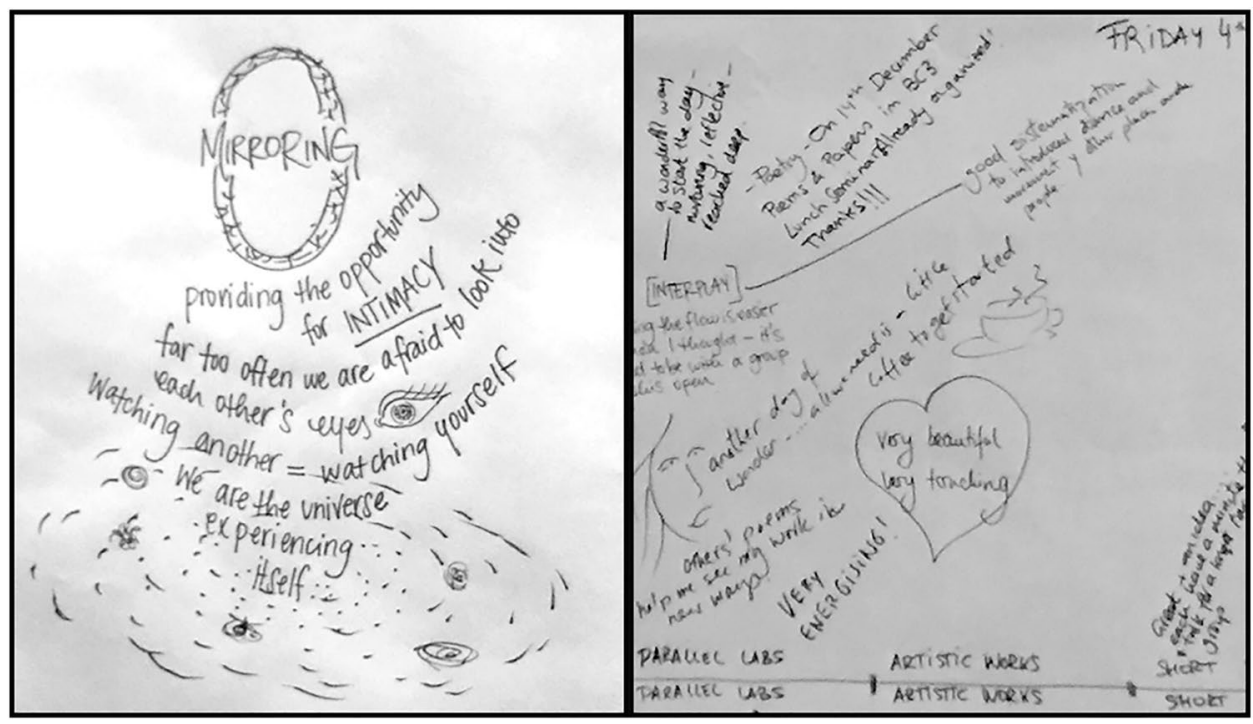

workshop sessions, their impressions and reflections on the methodological approaches (see Table 1). We received 17 responses out of 35 surveyed participants. A written report and a video abstract were created as an outcome of these observations and inputs.

The two lead authors of this paper performed a qualitative analysis of four streams of data collected: observation report, survey data, collective mural, and abstract texts received from selected participants. All sources were transcribed and coded using an iterative, directed approach to content analysis (Hsieh and Shannon 2005). First, based on participants' inputs during the workshop's opening and their application texts, we synthesised applicants' key motivations to get engaged in art-based approaches to sustainability, identifying five categories. These categories (expanding understanding beyond cognitive approaches, communication and awareness, dialogue and collaborations, shifting relations to others, exploration of alternative futures) were then used to conduct the analysis around two main themes: (i) methodological insights associated to the specific applications of arts-based practices explored within the workshop; and (ii) practical challenges and tensions operating within such arts-(sustainability)science interface (Figs. 3, 4).

\section{Results and discussion regarding the potential of integrating the arts within sustainability science}

This section presents and discusses five intertwined areas that outline the potential for arts-based research within sustainability, and identifies four emerging tensions and critical questions for further development of the field of arts-based sustainability. As an exploratory workshop, findings refer to the reflections and insights generated throughout the process, contextualised by literature on the field. Therefore, the aim of this analysis is not to assess the impact of the methodological approaches applied during the workshop, but to discuss their potential in the light of joint reflections between scientists, artists and practitioners and insights from the literature.

\section{Key areas of potential}

\section{Expanding understanding beyond cognitive approaches}

Some authors in recent years have called for an expansion of epistemological approaches within sustainability transformations research to acknowledge 'the qualitative complexity of human life, including its multisensorial and aesthetic dimensions' (Heinrichs and Kagan 2019, p. 431). Moreover, Dieleman and Huising (2006, p. 839), claimed that complex systems thinking can be enriched by "experiencing complex systems" which requires other-than-cognitive approaches to include emotions, intuition and corporal experiences.

During the workshop, participant sustainability scientists mentioned striving to engage with sustainability questions beyond rational ways of thinking and to incorporate wisdom and different forms of knowledge, including affective, emotional and corporal domains. Participants explored sustainability issues through, among others, the experiential qualities of body movement and performance (e.g. cartographic choreographies, 'interplay' method, voice and dance improvisation), the plasticity and suggestion of artistic works and the visual arts (e.g. sculpture, artist book, digital fabrication technologies, sound installation, documentary film), and the aesthetic contemplation and meditation in co-created crafts and installations (e.g. wicker weaving, co-created seeds' 

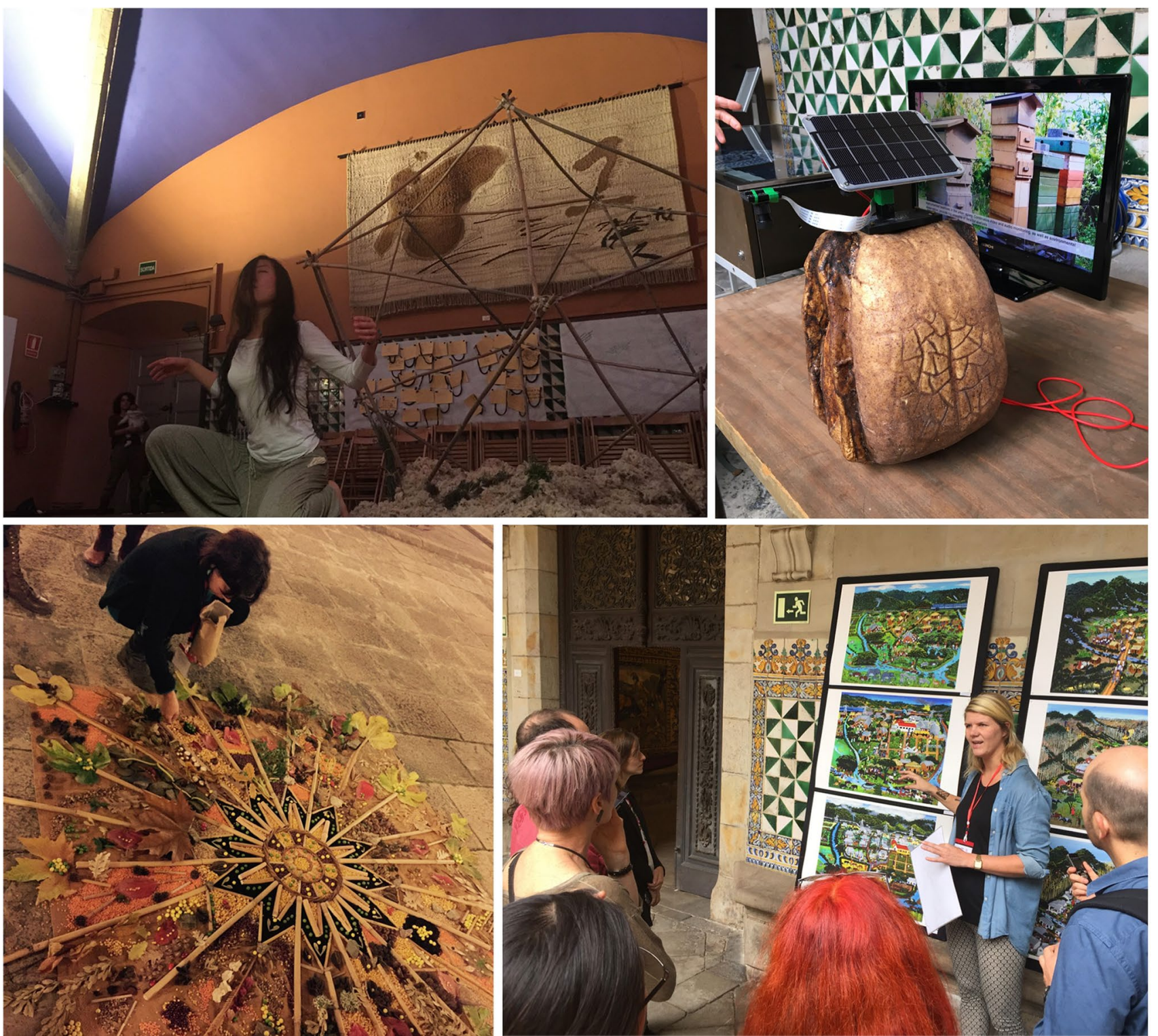

Fig. 3 Workshop participants were invited to experience a range of artistic practices as a way to explore potentials for arts-based sustainability. From top to bottom: movement and voice performance by Seshen Arts, presentation of the Guerilla Beehive by Anne Marie
Maes, mandala collective creation guided by Circles of Seeds, and presentation of paintings from Tanzanian local artist, by Emma Li Johansson. Pictures taken by David Tarrasón

everyday life/thoughts/activities have (in my body but also in the way I relate to others or to the environment that supports me).'

P16, researcher -artist

'The performative element of the interaction with other perspectives makes it easier to connect with topics that are relevant to me. Assuming that this happens also in other cases would explain that communication was easy and ideas emerged in a fluid way.'

$\mathrm{P} 3$, researcher 


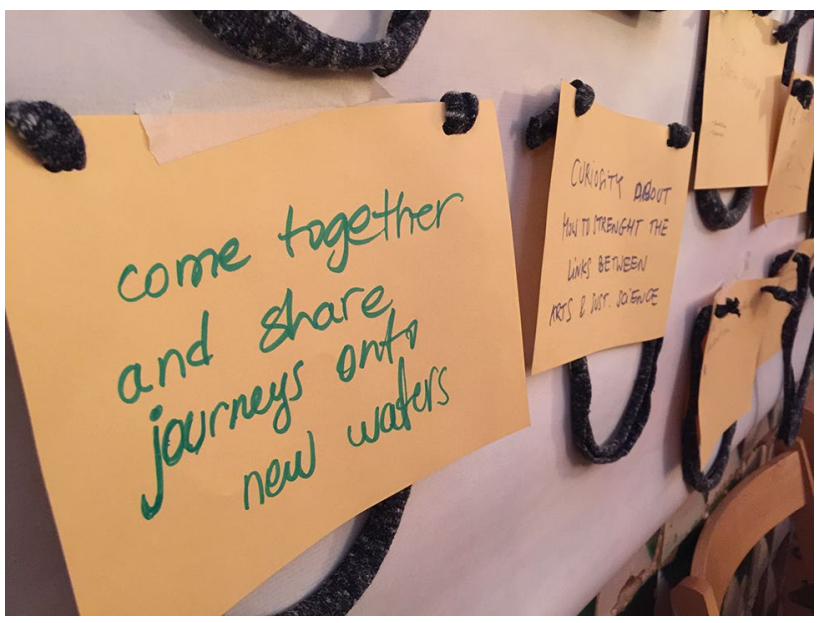

Fig. 4 A participant's purpose for the workshop, as written in their "life-jacket"

Providing alternative ways of sensing and apprehending sustainability may allow 'shifting complexity from the mind to find other ways of exploring and expressing it' (P14, researcher), through emotional/sensorial, participatory and performative approaches. The Gaia Lab, conducted by CACIS, invited participants to interact with "natural" materials through the five senses as a way to awaken our sensory perceptions and stimulate new ideas and affective connections, fostering meaningful reflections about our place and relationships within and with socio-ecological systems.

Several research streams have acknowledged the importance of engaging with more-than-cognitive approaches to. For example, based on the work of Haraway, Machin (2018) describes how bodily knowledge functions tacitly in engendering and guiding scientific research, therefore expanding the theoretical grounding supporting bodywork in research processes. Heinrichs and Kagan 2019 describe how aesthetic features of arts-based approaches can be particularly well placed to address the subjective, tacit and non-cognitive dimensions of sustainability that often fall outside standard methodologies of sustainability science. This includes questions of values, sense of identity, personal meaning, and emotions (anger, doubt, attachment, hope, inspiration). The provision of liminal spaces for exploration and renegotiation may afford thresholds allowing for ambiguity and the creation of new meanings, forms and structures of experience (Turner and Bruner 1986). In so doing, arts-based practices have the potential to open up new sources of reflexivity and reinvigorate a sense of purpose and willingness to engage in the co-creation of sustainable futures (Kagan 2011, Galafassi 2018b), counteracting the sometimes disempowering effect of scientific raw facts and statistics.
However, aesthetic experiences are culturally situated and located within different frames of reference (Greenwood 2011). As such, they might also be subjected to barriers in understanding and access and can also, in cases, be used to reinforce unsustainability (Kagan and Kirschberg 2016).

\section{Doing and communicating research}

Different experiences throughout the workshop shed insight on the contribution of art-based practices both for doing and communicating research, while revealing new dimensions of the data and offering alternative ways of presenting and disseminating research results. In the lab "Exploring the Art-Science-Sustainability Nexus with Poetic Analysis" by María Fernández-Giménez, participants used research materials and products to create poems, identify emergent insights, and reflect on the process of using poetry to do and communicate science. Two approaches to (science-based) poetic writing and analysis were shared: documentary poetry, in which qualitative data (e.g., interview transcripts) and scientific publications are the basis for poetry creation; and ethnographic poetry, in which research subjects create their own poems. In all of them, poetry's narrative wealth and its plethora of literary resources seemed key to allow for a fine-tune expression of complex meanings. For example, how poetry can grasp embedded contradictions in discourses, unmask power relations, display irony and humour, or integrate different voices in the same poem, being revelatory both about scientific and personal insights.

Such capacity of the arts for establishing new (aesthetic) connections and generating different meanings facilitates communication, but also invites self-reflection and criticism. In this line, the plastic art exhibition session experimented with expressive means and communication channels, transgressing conventional forms and creating new codes of communication and awareness- raising. The Intelligent Beehive, by Anne Marie Maes, proposed a guerrilla artistic intervention in which the research artwork becomes functional. The artist designed honeybees exploring DYT and new materials set in the city to raise critical questions about the pressing issue of bee colony collapse, measure pollution, and offer a shelter to support endangered bee species.

On the other hand, mainstream artistic media, such as film and audio-visuals, are well known for their ability to connect with wider audiences at different levels, given the influence of social media and visual culture. The versatility of the medium can lead to very different processes and aesthetics. Such diversity was reflected in the film session during the workshop, which introduced three different approaches to film-making, from a cinematic experience of human-nature relations to indie productions in community sustainability projects. 
Moreover, some sustainability researchers expressed frustration with conventional communication processes and found rewarding the work with arts-based approaches. They used scenario paintings (i.e. paintings illustrating future scenarios) and other forms of plastic arts as engaging boundary objects, with positive results in terms of both engagement with research participants and communication with other stakeholders.

Despite cautionary observations of instrumentalising or reducing art to communication (Bendor et al. 2017), insights gathered from the workshop go in line with further evidence on the potential of arts-based approaches to facilitate the analysis and communication of complex socio-ecological topics (Saratsi et al. 2019; Galafassi et al. 2018b; Curtis et al. 2012). By turning sustainability issues more experiential and concrete, and offering alternative means of communication, the arts offer diverse entry points for people and the possibility to connect cognitive with tacit and affective domains of knowledge, offering a deeper intuitive awareness (Benessia et al. 2012), while also overcoming the 'hegemony of the text' commonly dominating academic production (Conquergood 2002, p.151). Such processes of interaction and modes of expression aim not only at the transmission of knowledge about facts but instead they further expect to evoke the active construction and negotiation of meanings and connections in the audiences, contributing to sharing perspectives and building political and social consciousness (Leavy 2009, Rivera-López et al. 2018). All in all, arts-based approaches can have a wider reach and access to multiple and rich channels bringing science, even controversial research, beyond academia to the fore.

\section{Collaboration, dialogue, and power dynamics}

The normative sustainability research agenda, calls for inclusive transdisciplinary dialogues and participatory approaches that elicit, map and deliberate what values should guide sustainability transitions and how these processes might occur (Miller et al. 2013). Acknowledging power relations among stakeholder groups and between human and non-human elements of social-ecological systems and addressing them in participatory settings is seen as key within such participatory processes (Barnaud and Van Passen 2013). Challenging hierarchical relationships between researchers and participants becomes equally important when facilitating genuine collaborations beyond academia and generating shared action and political agendas (Rivera-López et al. 2018).

The potential of arts-based practices to trigger inclusive conversations and collaborations emerged as a major dialogical contribution of the approaches experienced. Participants noticed that a sense of trust and connection between people was created along the workshop through the invitation to experience without judgement and the building together of both playful and meaningful experiences (and insights) through different channels, encouraging a movement 'from dialogue to real engagement' (P10, researcher). This type of encounter seemed to foster human connection and possibilities for deep listening, resonance, mutual learning, and affect, as participants' reflections and external observations suggest. The creation of a safe-space, permitting the vulnerability of exposing oneself to others, was key to these disclosure processes. During the workshop, participants created and wore a metaphoric 'life-jacket' to navigate through the sessions, made out of their personal motivations to participate. A collective mural was created with them, reminding us of our participation purposes and inviting us to be aware of the spaces we were collectively creating. Some of the participants' reactions reflected this interpersonal dimension:

'The use of the body and communal activities and participation were shown to be key factors in building intimacy and the ability to work together'

$\mathrm{P} 2$, researcher-artist

'How my heart spills out so easily! Vulnerability. Cocreating a safe space to allow this'

Anonymous input in the mural

The workshop also unpacked the potential of arts-based practices to unveil tensions related to power dynamics within collaborations and inclusivity. By offering diverse languages and ways to connect with people and research participants, arts-based practices applied in the workshop showed their potential to include diverse voices into research and participatory processes. In the poetry workshop from Octavius Jones 'Knowing self and knowing another', aimed at exploring the potential of poetry to enhance people's sense of self and place, participants introduced themselves through a poem template that involved the use of childhood experiences and their connection to physical places. Participants perceived that the workshop approach, based on the disclosure of personal memories and identities, placed them on an equal level, in contrast to classical academic presentations, and set an intimate environment for inclusive discussion and deep sharing. In line with other art-based practices, including multiple perspectives was seen as a way of representing the unrepresented, of including the excluded. Moreover, inclusivity may foster not only recognition and visibility, but also emancipation. As artist Rodrigo Malvar argued in his presentation of the film Republika, there is an emancipatory potential when creating in the margins of the system:

'The sound performance Republika produces a sense of marginality (experimenting with new/other forms of relation between sound and performance) that radicalizes the process of emancipation, to create its own logic, a possible world, able to escape censure or disciplinary strategy emerging in the new democracy, 
making it out of the power of logic. It is argued that it is through a marginality without centre that emancipation, as a practice of resistance can happen.'

Similarly, the analysis of a scientific paper through the lenses of poetry in Fernández-Giménez's workshop helped participants critically reflect about their positioning within their research and their relation with the research participants, recognising and challenging the power position of science.

These findings are in line with previous research highlighting the contribution of arts-based participatory practices to build open and safe spaces for collaborative efforts to take root, based on common trust and empathic connections (Rivera-López et al. 2018; Heras and Tàbara 2014); but also for contestation, by providing alternative means of expression and 'vocabularies for human encounter with extreme environments' (Childs 2020, p.126, Ogaga 2011). Arts-based practices may also offer ways to manage power relations within collaborations, while drawing together different kinds of knowledge and inquiry (both legitimised and 'subjugated') and offering alternative communication and expression means, where 'subversive meanings and utopian yearnings' can emerge and be sheltered (Conquergood 2002, p. 148).

However, inclusivity is not to be presumed. Arts-based interactions can also cause disengagement when felt alien or difficult to access and thus be counter-productive in some situations. Especially for those participatory-art approaches, the success in engagement will partially rely on the selection of artistic forms and approaches adapted both culturally and to participants' abilities (Rivera-López et al., 2018). Hence, when planning arts-based interventions, it is fundamental to understand who is being engaged and with what purpose.

\section{Shifting relations to others and nature}

The sustainability quest is, in part, an interrogation of our ways of being in the world and relating with each other, including human and non-human beings (Orr 1992, O'Riordan 2013) - how people perceive, value and interact with the (natural) world fundamentally shapes the goals, values and paradigms that underpin human action (Abson et al. 2017) and influence environmental attitudes and behaviours. Finding ways to reconnect people with nature and other living and non-living beings has been highlighted as a key leverage point in sustainability transformations (Diaz et al. 2015; Abson et al. 2017). Such reconnection includes an awareness that acknowledges our interconnectedness in the web of life (Orr 1992).

Reconnecting people with nature and other beings involves delicate processes, including renegotiating perceptions, values and even identities. Some of the arts-based approaches shared in the workshop showed their potential to act as facilitators in such processes by promoting experiences of exploration and self-discovery, rooted in deep listening, empathy and resonance. When further transposed into the collective, these experiences opened up spaces of exchange with the potential to redefine our understanding of and relationships within socio-ecological systems, going beyond the description of attributes to make visible the web of values, relationships and affects that constitute our system. For instance, in the performative lab "Cartographic choreographies", Ignacio Díaz applied improvised choreographic dance, collectively created by the group, to explore notions of territory, identity, landscape and well-being. As part of the lab, each group was guided into creating a 'landscape movement bank', which was then transposed to the physical space of the room through a group choreography, representing the movement of well-being in their imagined landscapes. Rather than looking for a single representation of the landscape through movement, this approach intended to elicit the different cultural meanings attached to the landscape and deepen those values that foster well-being.

The fact that artists often operate from different paradigms and ask questions that have been forgotten or ignored opened -up new connections and possibilities to expand our understanding of sustainability issues. In this line, exhibitions and plastic works (based on sculpture, paintings, artistic notebook) were highlighted as powerful spaces where people could reassess their views on sustainability issues, by popping-up new questions and metaphors:

'Artists pose questions that scientists never do, in a very strange way ... because we have other paradigms, maybe because these questions are stupid... But it is precisely because of that reason, that sometimes our questions are more radical than the scientists' P19, artist

'The exhibited works gave me a fresh look: particularly the metaphor about the current (post-)crisis scenario and the balloons, and the Beehive project (integrating different transformative objectives and people involved)'

P16, researcher

Similarly, the artistic performances presented also mirrored conflicting perceptions and social constructions of nature, which prompted rich debates in the audience. The voice and movement performance by Seshen Arts, for instance, sought to inspire people "to find the natural landscape within their physical body and its expression", as described by the artist. In doing so, the piece raised the debate in the audience around arts' capacity to dissolve dichotomies between people and nature, while also identifying the risk of an idealisation of nature. Artists' 
work, just as the scientists', embodies different ontologies and value systems. When open to criticality and debate, artworks may act as powerful triggers for self-reflexivity about our own sustainability perceptions and what we project in our artworks.

The process of making was also explored, as the collective Wakeseed invited participants to co-create a mandala made of seeds and natural materials, to engage in different experiences with seeds through arts. This act was perceived as enhancing participants' communion through an intimate moment of co-creation, facilitating self and collective introspection and meditation about biodiversity and our relationships within and with the socio-ecological system and agri-food cultures. See for instance:

'I found very inspiring the seeds' mandala in order to trigger agrobiodiversity conservation awareness through aesthetics and self-introspection.'

$\mathrm{P} 1$, researcher

'Communal mandala can be done or used to build community and connect people to nature by gathering materials.'

$\mathrm{P} 2$, researcher-artist

In sum, by affecting sense of self and place, arts-based approaches can help to foster new social-ecological relations. Other experiences in the literature also echo this contribution, through arts capacity to emphasise aspects related to affect, belonging and identity, such as cultural meanings attached to the landscapes that communities inhabit (Rathwell and Armitage 2016; Fernández-Giménez 2015; Curtis 2009). At the collective level, acknowledging meaning and values embodied in places can also help participatory processes in sustainability research and transitions, while contributing to avoid potential conflicts associated with hidden agendas permeating the decision process (Schroeder 2013). At a more inner level, the potential of the arts to inspire new connections to nature may foster the encounter with more subtle forms of awareness about our position within the biosphere, in a range of modes, from dependency to impacts.

\section{Exploration of alternative futures}

Visioning is considered a key research and problemsolving method in transformative sustainability science (Wiek and Iwaniec 2014). Acknowledging the importance of visioning and scenario exercises to pursue sustainable futures, more pioneering efforts have been claimed within sustainability science for making future-oriented research more meaningful and relevant (Miller et al. 2013; OterosRozas et al. 2015). Providing rich, systemic descriptions of socio-ecological realities, challenging linear thinking while incorporating surprise and opportunity, or dealing with uncertainty beyond probabilistic terms have been identified as crucial to moving forward in this field (Miller et al. 2013; Wiek and Iwaniec 2014).

Our explorations in the workshop supported the idea of arts' capacity to unfold and communicate complexity in accessible ways and stimulate the imagination of alternative futures. The workshop 'Museums of the FutureNow' applied object-mediated storytelling to collectively imagine the future, while exploring the complex relationships between people and objects through time and the situated importance of things. During the session, participants were first invited to observe the Museum of Future Food, a collection of objects and stories fictionally portraying 'future history'. Then, they were divided in small groups and were given one object, a date in the future and a driver of change, to create and share their own story for the Museum. Crucial to such an exploration was the stimulation of social imagination brought by the de-contextualisation of every-day objects and their projection into the future, inviting participants to establish new connections and craft unexpected future landscapes. The storytelling format afforded a deep engagement of the participants, who collaboratively created a detailed and highly imaginative narrative about the future, yet meaningful to better understand our present. The resulting stories also reflected the different desires, anxieties, dreams and values which drive actions in the present, allowing to identify crosscultural patterns across different communities of practice, interest and place.

Further, engaging with sustainability is also seeking to visualise how alternative futures can be created in specific settings and have community members to discuss pathways to fair and sustainable futures. Emma Li Johansson shared one example of using scenario paintings in land-grabbing research, to let community members describe and visualise socio-environmental changes in their village, in collaboration with a local artist in Tanzania. Their experience showed how these paintings were informed by people affected, integrating local knowledge and experience into the artistic scenario projections and bringing their views to broader audiences and discussions.

other experiences in the literature also suggest that Artsbased approaches within sustainability can move forward the development of visions and future scenarios while offering intuitive, experiential, and less inhibited ways to explore and represent systems' dynamics and people's positions from different perspectives (Scheffer et al. 2015; Heras et al. 2016), and promoting open, communicative processes instead of conventional linear thinking and constrained visions of futures (Pereira et al. 2019). Such a way of engaging with complexity resists the idea of controlling the future and instead embraces ambiguity in a "commitment to the present" (Benessia et al. 2012), by deepening 
participants' appreciation and sensibilities to complexity at hand. The immersion in aesthetic experiences may afford spaces 'betwixt and between' where thresholds are renewed and unexpected patterns of relations, experiences and meanings can emerge (Turner and Bruner 1986). Further, the arts have proved their potential to strengthen emotional bonds between places and people, which lie at the base of personal motives for caring and acting (Inwood 2008; Kagan 2008). In this regard, the blending of art-led and science-led processes can help articulate the role of visioning 'as a process of making the future present' and placing oneself in relation to it, potentially 'infusing action' and a wider sense of purpose in participants (Galafassi et al. 2018a, p.8).

\section{Challenges: tensions and critical questions ahead}

\section{What is the role of the attitudes within sustainability science and the arts in facilitating or hindering collaborations?}

'I learned about different points of view. It was a surprise for me to see how much scientists are willing to break the rigidity of the academic rules.'

P13, artist

Understanding attitudes to arts-based hybrid practices within artistic and scientific disciplines and institutional settings, as well as ways to shift such attitudes towards collaborations, is important to move the field forward. Our workshop itself proved to be a way to affect participants' attitudes as it promoted a reflection on the views of sustainability sciences to the arts and of the arts to sustainability issues, which could entail mutual enrichment for both worlds. For instance, arts' regard to sustainability brought attention to subjectivity in sustainability research, the potential of multiple reflexivities beyond 'rational' types and of embodied approaches to meaning-making around sustainability. Similarly, although there are clear challenges in this joint venture, both researchers and artists perceived a change in attitudes towards and perceptions of the arts from the (normally rigid) scientific side, that is recently facilitating the flourishing of arts-sciences collaborations.

Hence, providing spaces of encounter where participants with diverse profiles can meet and discuss, but also critically experience different approaches they are not used to, seems crucial. Furthermore, expanding the sharing of arts-based experiences beyond circles already interested would highly contribute to breaking some stereotypes and enhance the legitimacy of these approaches as rigorous research practices. This is a movement already taking place in the last years, being reflected, for instance, in the growing field of Environmental Humanities (Oppermann and Iovino 2016;
Adamson 2019), or the increase in research and intervention calls funding arts-science experiences.

\section{How to work with tensions emerging in collaborations across paradigms, vocabularies and timelines?}

Despite the identified potentials, art-science experiences are not exempted from recurrent challenges that emerge both from the different epistemic and ontological worlds crossed by the arts and sciences, as well as the different implementation contexts and cultures. During and after the workshop, different conversations and comments emerged and critically reflected about these issues.

The most common challenge mentioned by participants is the irrefutable truth that arts and science practices operate through different paradigms and utilise different vocabularies. This includes the challenges of dealing with different notions of what counts as 'evidence' for knowledge, what is "good" and what is "impact" and "change". The correlation between impact and publication that still dominates most academic settings is an obstacle hindering more radical artscience transdisciplinary experiences. Finding relevant ways of assessment, both sensitive to the particularities of artsbased experiences and to the expectation of sustainability science research to contribute to transformative solutions is still a key area of development.

Generally speaking, the difficulty to articulate the intrinsic values of the arts often places too much attention on the evaluation of its instrumental impacts, with the risk of underestimating their aesthetic, communicative and cognitive development roles (Badham 2010). The assessment of arts-based approaches requires, thus, acknowledgement of such tensions (e.g. instrumental vs. aesthetical outcomes), finding a place from which the intrinsic values of the artistic experience can be recognised in addition to their educational, social or political impacts (Heras 2015). Research designs including arts-based practices in a significant way should also be open to a sense of experimentation, where the objective is 'to unfold rather than to solve issues' (Saratsi et al. 2019, p. 25). This includes allowing space and time for (unexpected) things to happen. In this regard, the different timing that sciences and arts operate may also pose practical challenges to collaboration or co-creation. Sometimes artistic production does not thrive well in strict and tight timelines, commonly associated with academic work. Collaborative processes require patience and trust, and highlight the need for face-to-face connection between participants. Mutually learning from and adapting to different requirements in terms of research design and time is thus both a challenge and a need to move forward within arts-based approaches in sustainability that expect to be socially and ecologically relevant. 
An additional tension between arts and science-based approaches might be the orientation. While output-oriented approaches prevail in science, process-oriented approaches are at the core of any artistic experience. Similarly, in the arena of sustainability, research processes are placed at the core of the objectives. Considering "the how" as a cornerstone for deep transformative potential, requires finding or building common ground between sciences and arts to acknowledge the power of the social creative process in itself, and placing it in the desired light. In sum, by challenging research epistemologies and assumptions, arts-based practices may bring new modes of thinking and criteria for judging research quality in terms that are meaningful within sustainability science. However, this will only be possible if there is an openness from both researchers and artists to learn from each other.

\section{How to deal with power dynamics and difficulties of integration?}

'I would like them (arts and sciences) to be more blended than integrated, and I don't see this much. I mean that I would like scientists to learn and use artistic methodologies as well as asking artists to comment on and interpret their work. And I would like artists to learn and use scientific methodologies, as well as asking scientists for advice and information.'

$\mathrm{P} 11$, artist.

The workshop also revealed a range of limitations and tensions related to power imbalances between artists and scientists that need to be taken into consideration. This is a multifaceted issue, ingrained in contemporary culture, that stems from different standards and understandings of results, process and quality, among others (Kjørup 2011). There has been traditionally a hierarchy between sciences and the arts, implying a higher recognition and status of science as a form of knowledge and a generalised lack of understanding about the nature of artistic knowledge and research from the sciences. Artists seemed to stress more this tension, emphasising challenges related to instrumental uses of the arts and the difficulty of a real integration of the arts within art-science collaborations. Although participants discussed this need for integration, we suggest it is important to pay attention to the process of integration as well to prevent entrenching existing differences in power dynamics of knowledge production.

Similarly, the artistic sector tends to be more precarious than the academic one. These aspects can affect employment relationships and the engagement of artists in arts-science experiences (Saratsi et al. 2019) and result, among others, in instrumental uses of the arts within art-science approaches or in a larger presence of scientific partners leading artsscience experiences.
A potential way to address these issues is to make such aspects explicit at an early stage of the collaboration and jointly address them. What kinds of collaborations do we want to create? And what do we need to sustain them? Who is at a disadvantage from the outset? Security of finding appropriate investment becomes crucial for both artists and scientists to get equally involved in arts-science experiences (Saratsi et al. 2019). Also better understanding each other's practices and equally recognising their contributions, in their diversity, is a must to allow deep collaborations and overcome hierarchies. This might require as well a better training on and accurate understanding of inter- and transdisciplinary collaborations. The creation of long-term interactions and alliances between academic and artistic institutions and settings, becomes essential to create institutional contexts favouring more balanced and sustainable arts-science experiences in the long-run.

\section{Does the concept of sustainability stand in the way of more productive collaborations?}

'Sustainability is also a buzzword in arts. Sustainable arts, photo sessions or exhibitions (...). But are we talking about the same idea? Are we only "painting in green"?'

P20, Artist

Just as a certain reluctance to engage with the arts is sometimes expressed from scientific settings, during the workshop artists raised critical questions about their engagement with sustainability issues. Among them, the term 'sustainability' was itself discussed, as a potential barrier to meaningful engagement with socio-ecological transformations. Some artists expressed their scepticism about and rejection of the term 'Sustainability', which they perceived as ambiguous and overused. In this regard, two artists missed more time in the workshop to collectively explore and discuss sustainability as an issue. Whether sustainability might act as an umbrella term grouping a myriad of diverse actors working on the common ground of socio-ecological transformations, or rather will divert such arts-based transformative efforts is still to be seen. However, this discussion highlights the situated importance of the term sustainability and its procedural dimension (Robinson 2008). Just as it happens within sustainability science, attributes associated with sustainability cannot be taken for granted in arts-based interventions, nor should be the projections of sustainability embodied in artworks overlooked. If the arts can make a contribution to sustainability, it is precisely due to their capacity to critically and insightfully question and build new layers of meaning, helping us create and negotiate fresh, rich and nuanced understandings around it. 


\section{Limitations of the workshop}

Finally, participants also reflected about weaknesses and limitations of the workshop. Although the experiential approach was generally appreciated, many participants also considered the high number of sessions in only two days as an important limitation. Particularly, more time for reflection and expanded debates after each session, and less activities programmed each day, were identified by participants as key needs to explore and frame themes more fully and digest the proposals experienced. Some participants also suggested expanding the invitation beyond the interface art-(sustainability)science to include other relevant actors in the discussion. Open events for the general public or more diverse profiles in the workshop sessions were suggested for future editions. In this regard, for instance, there were no practitioners from the business community, which is also an important actor in socio-ecological transformations. Finding venues outdoors or outside the city was also suggested as a way to further facilitate different kinds of connection to spaces and landscapes, and different group dynamics.

Furthermore, while focusing on a joint analysis between artists, researchers and practitioners, our data collection does not explicitly attend to the possible differences in perceptions between artists and scientists. While acknowledging that many transdisciplinary researchers have a hybrid background, understanding different experiences of collaborations between artists and scientists is a crucial area of future research for the design of such interactions. Further joint experiences in the field would, thus, benefit from an analysis of this kind to better inform the critical questions identified and delineate future practical actions to improve and facilitate deeper collaborations.

\section{Conclusion: towards a community of practice}

In recent years, a profusion of methods, experiences and practices have emerged in the interface between arts and sustainability science and several claims have been made by sustainability scientists about the role of arts-based approaches in supporting sustainability research. In this article, we have discussed reflections emerging from a workshop that brought together artists, scientists and practitioners around sustainability issues to jointly explore and analyse the potentials for an arts-based sustainability research.

Overall, the workshop has pointed towards five key areas of potential, i.e. embracing more-than-cognitive aspects of knowledge, improving communication, grappling with power dynamics, shifting relationships to nature, and facilitating the envisioning of alternative futures. Although the insights from this workshop are certainly conditioned to the range of participants, art practices present and sustainability science concerns and questions, we speculate that these insights may be generalisable to other practices too.

Although arts-based approaches are not a panacea towards central challenges of sustainability research, our exploration suggests there are yet untapped resources and experiences within the field, and collaborative approaches with artists and practitioners are likely to generate benefits for sustainability research and practice.

Further, joint reflections also pointed to tensions and limitations in the hybridisation of the arts and sustainability sciences. These include accessibility, aptitude, research design or cultural appropriateness. To fully materialie collaborations between arts and sciences, a set of key conditions are needed, such as mutual trust, equal recognition, supporting infrastructure-funding, appropriate time-frames, or overcoming hierarchies. Similarly, our results suggest that there are specific competencies required to operate in this interface, such as the ability to navigate power imbalances and foster transparency, to choose appropriate collaborations or to understand disciplinary possibilities as well as limitations. This includes reflexivity on the meaning of roles of "facilitator', "artist', "researcher" in the process.

The creation of a critical community of practice is also crucial to mutually learn from and address emerging challenges and possibilities within this field. In particular how diverse and disperse initiatives can be shared and connected, discussed and enriched, expanded in space and rooted in local action. We are aware that building a community requires time and resources. By further sharing this experience outside participants, we hope this article can contribute to methodologically inspire other encounters ( the workshop could be proposed as a tool), as well as to critically raise questions and insights into the challenges and how to leverage the potential of the arts to respond to global environmental challenges while boosting societal transformations. Further workshops and joint encounters would benefit from more reflective spaces, a more nuanced analysis of different actors' needs and self-identification, more practical links with sustainability transformations and a wider diversity of actors involved beyond artists and scientists. With a growing urgency it is important to devise rich ways to grapple and respond to sustainability challenges.

Supplementary Information The online version contains supplementary material available at https://doi.org/10.1007/s11625-021-01002-0.

Acknowledgements We deeply thank the 43 participants of the workshop, as well as the colleagues who generously supported us in its implementation. Thanks Josep M. Espelta for the coordination work, Elena Galán, Isabel Díaz Reviriego and Marién González Hidalgo for being rapporteurs, and David Tarrasón and Vanessa del Campo Gatell for their pictures and filming. The workshop was also possible thanks 
to the sponsorship and cooperation of the Institut d'Estudis Catalans, Societat Catalana de Biologia, Escola Massana, University of Hohenheim, ICAAM-Universidade de Évora, Universidad Pablo Olavide, Universitat Autònoma de Barcelona, Universitat Oberta de Catalunya, CREAF and Cambio. I. Ruiz-Mallén is also thankful to the Spanish government's Research Agency through a 'Ramón y Cajal' research fellowship (RYC-2015-17676). E.Oteros-Rozas has been funded by Juan de la Cierva Incorporation Fellowship of the Ministry of Science Innovation and Universities (IJCI-2017-34334). Diego Galafassi acknowledges Swedish Formas project Arts For Realising the Sustainable Development Goals (Arts4SDGs). The experience of the workshop was presented at the Resilience Conference 2017 in Stockholm, Sweden. We thank comments and questions by participants of the session and for this Journal anonymous reviewers.

Funding Open access funding provided by Lund University.

Open Access This article is licensed under a Creative Commons Attribution 4.0 International License, which permits use, sharing, adaptation, distribution and reproduction in any medium or format, as long as you give appropriate credit to the original author(s) and the source, provide a link to the Creative Commons licence, and indicate if changes were made. The images or other third party material in this article are included in the article's Creative Commons licence, unless indicated otherwise in a credit line to the material. If material is not included in the article's Creative Commons licence and your intended use is not permitted by statutory regulation or exceeds the permitted use, you will need to obtain permission directly from the copyright holder. To view a copy of this licence, visit http://creativecommons.org/licenses/by/4.0/.

\section{References}

Abson DJ, Fischer J, Leventon J, Newig J, Schomerus T, Vilsmaier U, Lang DJ (2017) Leverage points for sustainability transformation. Ambio 46(1):30-39

Adamson J (2019) Las humanidades ambientales globales: ampliando la conversación imaginando futuros alternativos. In: Albelda J, Parreño JM, Henríquez-Marrero JM (eds) Humanidades Ambientales Pensamiento, arte y relatos para el Siglo de la Gran Prueba. Los Libros de la Catarata, Madrid, pp 15-33

Badham M (2010) The Menace of Measurement: a discussion about arts indicators. University of Melbourne

Bailey K (1994) Sociology and the new systems theory: toward a theoretical synthesis. SUNY Press, Albany

Barnaud C, Van Paassen A (2013) Equity, power games, and legitimacy: dilemmas of participatory natural resource management. Ecol Soc 18(2):21. https://doi.org/10.5751/es-05459-180221

Barone T, Eisner EW (2012) Arts based research. Sage Publications, Los Angeles

Bendor R, Maggs D, Peake R, Robinson J, Williams S (2017) The imaginary worlds of sustainability: observations from an interactive art installation. Ecol Soc 22:2

Benessia A, Funtowicz S, Bradshaw G, Ferri F, Ráez-Luna EF, Medina CP (2012) Hybridizing sustainability: towards a new praxis for the present human predicament. Sustain Sci 7(1):75-89

Blanc N, Benish BL (2017) Form, Art and the Environment. Engag Sustain. https://doi.org/10.4324/9781315660370

Boal A (2006) The aesthetics of the oppressed. Routledge

Cash DW, Clark WC, Alcock F, Dickson NM, Eckley N, Guston DH, Mitchell RB (2003) Knowledge systems for sustainable development. Proc Natl Acad Sci 100(14):8086-8091

Childs J (2020) Performing 'blue degrowth': critiquing seabed mining in Papua New Guinea through creative practice. Sustain Sci 15:117-129. https://doi.org/10.1007/s11625-019-00752-2
Chilton G, Leavy P (2014) Arts-based research practice: merging social research and the creative arts. The Oxford handbook of qualitative research. Oxford University Press, New York, pp 403-422

Clark WC, Lorrae van Kerkhoff LL, Gilberto CG (2016) Crafting usable knowledge for sustainable development. Proc Natl Acad Sci 113(17):4570-4578. https://doi.org/10.1073/pnas.16012 66113

Conquergood D (2002) Performance studies: interventions and radical research. Drama Rev 46(2):145-156

Curtis DJ (2009) Creating inspiration: the role of the arts in creating empathy for ecological restoration. Ecol Manag Restor 10(3):174184. https://doi.org/10.1111/j.1442-8903.2009.00487.x

Curtis DJ, Reid N, Ballard G (2012) Communicating ecology through art: what scientists think. Ecol Soc 17(2):3. https://doi.org/10. 5751/ES-04670-170203

Dahlstrom MF (2014) Using narratives and storytelling to communicate science with nonexpert audiences. Proc Natl Acad Sci 111(Supplement 4):13614-13620. https://doi.org/10.1073/pnas. 1320645111

Díaz S, Demissew S, Carabias J, Joly C, Lonsdale M, Ash N, Larigauderie A, Adhikari JR, Arico S, Báldi A, Bartuska A (2015) The IPBES conceptual framework-connecting nature and people. Curr Opin Environ Sustain 14:1-16

Dieleman H, Huisingh D (2006) Games by which to learn and teach about sustainable development: exploring the relevance of games and experiential learning for sustainability. J Clean Prod 14(9-11):837-847

Eisner EW (2002) The arts and the creation of mind. Yale University Press

Fazey I, Schäpke N, Caniglia N, Patterson J, Hultman J, van Mierlo B, Säwe F (2018) Ten essentials for action-oriented and second order energy transitions, transformations and climate change research. Energy Res Soc Sci 40:54-70. https://doi.org/10.1016/j.erss.2017. 11.026

Feola G (2015) Societal transformation in response to global environmental change: a review of emerging concepts. Ambio 44(5):376390. https://doi.org/10.1007/s13280-014-0582-z

Fernández-Giménez ME, Jennings LB, Wilmer H (2019) Poetic inquiry as a research and engagement method in natural resource science. Soc Nat Resour 32(10):1080-1091

Fernández-Giménez ME (2015) "A shepherd has to invent” Poetic analysis of social-ecological change in the cultural landscape of the central Spanish Pyrenees. Ecol Soc 20:4

Ferraro E, Reid L (2013) On sustainability and materiality. Homo faber, a new approach. Ecol Econ 96:125-131. https://doi.org/10.1016/j. ecolecon.2013.10.003

Gabrys J, Yusoff K (2012) Arts, sciences and climate change: practices and politics at the threshold. Sci Cult 21(1):1-24. https://doi.org/ 10.1080/09505431.2010.550139

Galafassi D, Kagan S, Milkoreit M, Heras M, Bilodeau C, Bourke SJ, Merrie A, Guerrero L, Pétursdóttir G, Tàbara JD (2018a) 'Raising the temperature': the arts on a warming planet. Curr Opin Environ Sustain 31:71-79

Galafassi D, Heras M, Tàbara JD (2018b) Restoring our senses, restoring the earth. Fostering imaginative capacities through the arts for envisioning climate transformations. Elem Sci Ant 6:69

Greenwood J (2011) Aesthetic learning, and learning through the aesthetic. In: Schonmann S (ed) Key concepts in theatre/drama education. Sense Publishers, Rotterdam, pp 47-52

Grenni S, Soini K, Horlings LG (2020) The inner dimension of sustainability transformation: how sense of place and values can support sustainable place-shaping. Sustain Sci 15(2):411-422

Haraway DJ (1999) Situated knowledges: the science question in feminism and the privilege of partial perspective. In: Biagioli M (ed) The science studies reader. Routledge 
Heinrichs H, Kagan S (2019) Artful and sensory sustainability science: exploring novel methodological perspectives. Revista De Gestão Ambiental e Sustentabilidade 8(3):431-442

Heras M, Tàbara JD (2014) Let's play transformations! Performative methods for sustainability. Sustain Sci 9(3):379-398. https://doi. org/10.1007/s11625-014-0245-9

Heras, M (2015) Towards new forms of learning: exploring the potential of participatory theatre for sustainability science. $\mathrm{PhD}$ dissertation. Institut de Ciencia i Tecnologia Ambiental (ICTA), Universitat Autònoma de Barcelona, Barcelona.

Heras M, Tábara JD, Meza A (2016) Performing biospheric futures with younger generations: a case in the MAB Reserve of La Sepultura. Mexico Ecol Soc 21(2):14. https://doi.org/10.5751/ ES-08317-210214

Horlings LG (2015) The inner dimension of sustainability: personal and cultural values. Curr Opin Environ Sustain 14:163-169. https://doi. org/10.1016/j.cosust.2015.06.006

Hsieh HF, Shannon SE (2005) Three approaches to qualitative content analysis. Qual Health Res 15:1277-1288

Hughes C, Lury C (2013) Re-turning feminist methodologies: from a social to an ecological epistemology. Gend Educ 25(6):786-799. https://doi.org/10.1080/09540253.2013.829910

Inwood HJ (2008) At a crossroads: situating place-based art education. Can J Environ Educ 13(1):29-41

Johnson M (2010) Embodied knowing through art. In: Biggs M, Karlsson $\mathrm{H}$ (eds) The Routledge companion to research in the arts. Routledge, pp 171-181

Kagan S (2008) Sustainability: a new frontier for the arts and cultures. Vas Verlag Fur Akademisch, Frankfurt

Kagan S (2011) Aesthetics of sustainability: a transdisciplinary sensibility for transformative practices. Transdiscip J Eng Sci 2:65-73

Kagan S, Kirschberg V (2016) Music and sustainability: organizational cultures towards creative resilience - a review. J Clean Prod 135:1487-1502

Kauffman S (1996) At home in the universe: the search for the laws of self-organization and complexity. Oxford University Press, New York

Kjørup S (2011) Pleading for plurality: artistic and other kinds of research. In: Biggs M, Karlsson H (eds) The Routledge companion to research in the arts. Routledge, New York, pp 24-43

Kolb DA (1984) Experiential learning: experience as the source of learning and development. Prentice-Hall, New Jersey

Leavy P (2009) Method meets art: arts-based research practice. The Guilford Press, New York

Leavy P (2018) Handbook of arts-based research. Guilford Press, New York

Machin A (2018) Bodies of knowledge and knowledge of bodies: "we can know more than we can tell.” Epistemol Philos Sci 55(4):84-97

McNiff S (2008) Arts-based research. In: Knowles JG, Cole AL (eds) Handbook of the arts in qualitative research: perspective, methodologies, example and issues. Sage Publications, Thousand Oaks, pp 83-92

McNiff S (2011) Artistic expressions as primary modes of inquiry. Br J Guid Couns 39(5):385-396

Milkoreit M (2017) Imaginary politics: climate change and making the future. Elem Sci Anth 5:62. https://doi.org/10.1525/elementa.249

Miller TR, Wiek A, Sarewitz D, Robinson J, Olsson L, Kriebel D, Loorbach D (2013) The future of sustainability science: a solutions-oriented research agenda. Sustain Sci 9(2):239-246

O'Brien $\mathrm{K}$ (2018) Is the $1.5^{\circ} \mathrm{C}$ target possible? Exploring the three spheres of transformation. Curr Opin Environ Sustain Sustain Govern Trans 31:153-160. https://doi.org/10.1016/j.cosust.2018.04.010

Ogaga O (2011) Rethinking militancy and environmental justice: the politics of oil and violence in Nigerian popular music. Afr Today 58:79-101
Oppermann S, Iovino S (2016) Environmental humanities: voices from the anthropocene. Rowman \& Littlefield International, London

O'Riordan T (2013) Future earth and tipping points. Environ Mag $55(5): 31-40$

Orr D (1992) Ecological literacy: education and the transition to a postmodern world. State University of New York Press, Albany

Oteros-Rozas E, Martín-López B, Daw T, Bohensky EL, Butler J, Hill R, Martin-Ortega J, Quinlan A, Ravera F, Ruiz-Mallén I, Thyresson M, Mistry J, Palomo I, Peterson GD, Plieninger T, Waylen KA, Beach D, Bohnet IC, Hamann M, Hanspach J, Hubacek K, Lavorel S, Vilardy S (2015) Participatory scenario planning in place-based social-ecological research: insights and experiences from 23 case studies. Ecol Soc 20(4):32. https://doi.org/10.5751/ES-07985-200432

Pereira L, Sitas N, Ravera F, Jimenez Aceituno A, Merrie A (2019) Building capacities for transformative change towards sustainability: imagination in intergovernmental science-policy scenario processes. Elementa 7(1):35. https://doi.org/10.1525/elementa.374

Pröpper MH (2017) Sustainability science as if the world mattered: sketching an art contribution by comparison. Ecol Soc 22:3

Rathwell KJ, Armitage D (2016) Art and artistic processes bridge knowledge systems about social-ecological change: An empirical examination with Inuit artists from Nunavut, Canada. Ecol Soc 21(2):21. https://doi.org/10.5751/ES-08369-210221

Rivera Lopez F, Wickson F, Hausner VH (2018) Finding CreativeVoice: applying arts-based research in the context of biodiversity conservation. Sustainability 10(6):1778

Robinson J (2008) Being undisciplined: transgression and intersections in academia and beyond. Futures 40(1):70-86

Ruiz-Trejo MG, García-Dauder D (2019) Epistemic-corporeal workshops: putting strong reflexivity into practice. Tapuya 2(1):42-58

Sachs JD, Schmidt-Traub G, Mazzucato M, Messner D, Nakicenovic N, Rockström J (2019) Six transformations to achieve the sustainable development goals. Nat Sustain 2(9):805-814. https://doi.org/10. 1038/s41893-019-0352-9

Saratsi E, Acott T, Allinson E, Edwards D, Fremantle C, Fish R (2019) Valuing arts and arts research. Valuing Nature Paper VNP 22.

Scheffer M, Bascompte J, Bjordam TK, Carpenter SR, Clarke LB, Folke C, Marquet P (2015) Dual thinking for scientists. Ecol Soc 20(2):3. https://doi.org/10.5751/ES-07434-200203

Schroeder H (2013) Sensing value in place. In: Stewart WP, Williams DR, Kruger LE (eds) Place-based conservation: perspectives from the social sciences. Springer, Dordrecht, pp 73-87. https://doi.org/ 10.1007/978-94-007-5802-5_6

Tàbara JD, Chabay I (2013) Coupling human information and knowledge systems with social- ecological systems change. Refram Res Educ Policy Sustain Environ Sci Policy 28:71-81

Turner V, Bruner EM (1986) The anthropology of experience. PAJ Publications, New York

Westley F, Olsson P, Folke C, Homer-Dixon T, Vredenburg H, Loorbach D, Thompson J, Nilsson M, Lambin E, Sendzimir J, Banerjee B, Galaz V, van der Leeuw S (2011) Tipping toward sustainability: emerging pathways of transformation. Ambio 40(7):762. https://doi. org/10.1007/s13280-011-0186-9

Wiek A, Withycombe L, Redman CL (2011) Key competencies in sustainability: a reference framework for academic program development. Sustain Sci 6(2):203-218

Wiek A, Iwaniec D (2014) Quality criteria for visions and visioning in sustainability science. Sustain Sci 9(4):497-512

Wiek A, Lang DJ (2016) Transformational sustainability research methodology. Sustainability science. Springer, Dordrecht, pp 31-41

Publisher's Note Springer Nature remains neutral with regard to jurisdictional claims in published maps and institutional affiliations. 